\title{
SELETIVIDADE DE PRODUTOS FITOSSANITÁRIOS UTILIZADOS NA CULTURA DO MORANGUEIRO A PHYTOSEIULUS MACROPILIS (BANKS) (ACARI: PHYTOSEIIDAE) EM CONDIÇÕES DE LABORATÓRIO
}

\author{
Bruce Veronez - Mestrando do Instituto Biológico, Campinas, São Paulo - bruce_veronez@yahoo.com.br \\ Luiz Carlos Dias Rocha - IF Sul de Minas Gerais - Campus Inconfidentes - luiz.ifet@gmail.com \\ Juliano Antonio de Freitas - IF Sul de Minas Gerais - Campus Inconfidentes - Bolsista de Iniciação científica \\ Juliano.eafi@yahoo.com.br \\ Cynthia Alves Sena - cyzinha22@hotmail.com \\ Lívia Maria Alves Porto - liviamap@hotmail.com \\ Sueila Silva - su_sueila@hotmail.com
}

\section{RESUMO}

O morangueiro (Fragaria $x$ ananassa Duch) representa hoje uma das mais importantes culturas agrícolas do Sul de Minas Gerais, e também relevante no cenário nacional. É intenso o emprego de agrotóxicos no manejo de pragas nessa cultura. Dentre as pragas, os ácaros destacam-se pelo seu alto potencial biótico, elevado prejuízo provocado aos agricultores e pela grande dificuldade de controle com agrotóxicos convencionais devido ao surgimento de populações resistentes dessa praga na cultura. Para realizar o controle do ácaro-praga Tetranychus urticae Koch (Acari: Tetranychidae), o predador Phytoseiulus macropilis (Banks) (Acari: Phytoseiidae) vem sendo empregado em lavouras de morango dessa região com sucesso. Porém, alguns pesticidas causam efeito nocivo a essa espécie de predador. Perante esse problema, torna-se necessário estudos com agrotóxicos que possam ser inócuos ao ácaro predador e possuam um baixo espectro de ação, podendo, serem utilizados na Produção Integrada de Morango (PIMo). O objetivo do trabalho foi avaliar a seletividade de produtos fitossanitários utilizados na cultura do morangueiro a P. macropilis em condições de laboratório. Foram conduzidos três bioensaios no Laboratório de Controle Biológico do Instituto Federal do Sul de Minas Gerais, Campus Inconfidentes. Os produtos testados, em $g$ de i.a. $\mathrm{L}^{-1}$ de água foram: abamectina $(0,1)$, fempropatrina $(0,065)$, propargito $(0,03)$, iprodiona $(0,15)$, azoxistrobina $(0,02)$ e enxofre $(0,3)$. Avaliaram-se o efeito dos compostos sobre a mortalidade dos indivíduos por meio da aplicação direta sobre adultos de P. macropilis, da ingestão de presas contaminadas, e do contato dos predadores com superfícies tratadas. Independente da forma de contato, abamectina mostrou-se prejudicial a $P$. macropilis. Fempropatrina, propargito, iprodiona, azoxistrobina e enxofre não afetaram o predador e foram classificados como inócuos para esse predador em condições de laboratório, segundo escala de toxicidade proposta pela IOBC. Compostos seletivos podem ser empregados no manejo integrado de pragas em morangueiros em associação com o predador P. macropilis.

Palavras-chave: morangueiro, seletividade, ácaro-rajado, ácaro predador, Phytoseiulus macropilis.

\section{ABSTRACT}

The Strawberry crop (Fragaria $x$ ananassa Duch) is very important agricultural crop in South of state of the Minas Gerais, and also relevant in Brazil. In this crop, is intensive the use of pesticides for the integrated pest management (IPM). Among the pest, the mites highlight for your high biotic potential, damage caused to the farmers and control difficulty with conventional pesticides. For the Tetranychus urticae Koch (Acari: Tetranychidae) control, the predator Phytoseiulus macropilis (Banks) (Acari: Phytoseiidae) it has been used in strawberry crop with successful. Ho- 
wever, the biological control with P. macropilis it has been harmed by the disordered application of pesticides in the strawberry crop, that are harmful for this species. Thus, this necessary the realization of the researches whit pesticides that can be innocuous to the mite predator, and present a low action spectrum, still being able to, they be used in the Integrated Production of Strawberry (PIMo). The aim of this work was to evaluated the selectivity of pesticides used in strawberry crop on $P$. $m a-$ cropilis in laboratory conditions. The bioassays was carried out in the Laboratory of Biological Control of Federal Institute of South of Minas Gerais, Campus Inconfidentes, Brazil. The compounds tested in $\mathrm{g}$ of a.i. $\mathrm{L}^{-1}$ of water were: abamectin (0.1), fenpropathrin (0.065), propargite $(0.03)$, iprodione $(0.15)$, azoxystrobin (0.02) and sulfur (0.3). The effect of direct application of compounds, consumption of contaminated pray and direct contact of surfaces treated whit predators on mortality of $P$. macropilis adults was evaluated. Independent of contact way, abamectin showed harmful to P. macropilis. Fenpropathrin, propargite, iprodione, azoxystrobin and sulfur didn't affect the predator and were classified as selective for that predator in laboratory conditions, second toxicity scale proposed by IOBC members. Selective compounds can be used in the IPM in strawberry crop in association with the predator P. macropilis.

Key-words: strawberry crop, selectivity, twospotted spider mite, predator mite, Phytoseiulus macropilis.

\section{INTRODUÇÃO}

O morangueiro (Fragaria $x$ ananassa Duch) representa hoje uma das mais importantes culturas agrícolas do Sul de Minas Gerais, além de ser uma cultura também relevante no cenário nacional com uma área cultivada ultrapassa os 3.500 ha e produção superior a 100 mil toneladas por ano. Minas Gerais, São Pau- lo e Rio Grande do Sul destacam-se, como os maiores produtores (Antunes et al., 2007).

Em Minas Gerais a produção concentra-se na região sul do estado, ocupando uma área aproximada de 1.200 ha. Os cultivos são em sua maioria em pequenas propriedades, que praticam agricultura familiar, sendo uma cultura de grande relevância pelo elevado emprego de mão-de-obra (Resende et al., 1999). Recentemente, em conseqüência da elevada susceptibilidade da cultura e de equívocos de manejo praticados por agricultores, o morangueiro tem sido uma das culturas com maior utilização pesticidas, na tentativa de combater a ocorrência de pragas que é um dos principais problemas que vêm afetando o desempenho das lavouras.

Dentre as pragas que ocorrem na cultura, os ácaros destacam-se pelo seu alto potencial biótico, elevado prejuízo provocado aos agricultores e dificuldade de controle com produtos fitossanitários convencionais. $\mathrm{O}$ ácaro-rajado Tetranychus urticae Koch (Acari: Tetranychidae) tem provocado grandes perdas em culturas do morangueiro no Sul de Minas Gerais. Os ácaros se alimentam do conteúdo intracelular das folhas, causam a morte das células atacadas e provocam o aparecimento de manchas ou áreas descoradas (Simões et al., 2007), e em altas densidades podem reduzir a taxa fotossintética por causarem danos às células do mesófilo foliar e o fechamento dos estômatos, causando a redução na quantidade e no peso dos frutos (Fadini \& Alvarenga, 1999).

Nas lavouras de morangueiros da região, o controle do ácaro-rajado é realizado principalmente pelo método químico e nos últimos anos tem sido dificultado pela ocorrência de populações resistentes a importantes ingredientes ativos dos produtos fitossanitários utilizados (Sato et al., 1994). Além disso, proporciona um arriscado espaço para o emprego de agrotóxicos que não possuem registro para uso na cultura e um aumento no número de pulverizações, na tentativa de se chegar a 
um nível significativo de controle desse ácaropraga.

A predominância do controle químico, além de comprometer a qualidade do produto final, pode ser bastante impactante ao meio ambiente e aos agricultores, além disso, interfere na ação dos inimigos naturais que podem ser eficientes no controle de ácaros e insetospraga (Van de Vrie et al., 1972). Nos agroecossistemas esses inimigos naturais podem ocorrer naturalmente e constituem uma ferramenta importante no controle de pragas, uma vez que o predador pode se alimentar de indivíduos resistentes e susceptíveis.

Estudos têm demonstrado que ácaros predadores da família Phytoseiidae são os mais abundantes e têm como alimento básico ácaros tetraniquídeos (McMurtry et al., 1970; McMurtry \& Croft, 1997 e Moraes, 2002). Entre os predadores, Phytoseiulus macropilis (Banks) (Acari: Phytoseiidae), ocorre naturalmente em morangueiro e, segundo Garcia \& Chiavegato (1997), apresentam grande eficiência predatória para o controle de T. urticae. Estudos relacionados à biologia desse predador realizados por Ali (1998) e Silva et al. (2005) concluíram que $P$. macropilis apresenta melhor desenvolvimento com temperaturas entre $23^{\circ} \mathrm{C}$ e $26^{\circ} \mathrm{C}$ e que tem grande potencial para o controle biológico do ácaro-rajado.

Entretanto, para a viabilização de programas de manejo integrado ou de produção integrada em morangueiros, é importante que os produtos fitossanitários utilizados na cultura sejam inócuos ou seletivos aos inimigos naturais utilizados para o controle biológico e que estudos de seletividade sejam incentivados em condições laboratório, semicampo e campo (Wetzel \& Dickler, 1994). Recentemente, pesquisadores de Universidades e Institutos Federais, centros de pesquisas como Embrapa e Epamig e técnicos de instituições de extensão (Emater) tem dedicado esforços para produção de conhecimentos necessários à implementação do sistema de produção in- tegrada de morango no Brasil. No entanto, estudos relacionados à seletividade dos produtos fitossanitários aos principais predadores encontrados na lavoura ainda são escassos.

Neste sentido, objetivou-se no presente estudo avaliar a seletividade de produtos fitossanitários utilizados na cultura do morangueiro a $P$. macropilis, em condições laboratoriais, necessária à implementação de estratégias de manejo integrado de pragas e/ou produção integrada na cultura do morangueiro compatíveis com utilização desse predador. $\mathrm{O}$ trabalho teve como objetivos específicos: a) selecionar produtos fitossanitários utilizados na cultura do morangueiro, inócuos ou de baixa toxicidade ao predador P. macropilis; b) fornecer subsídios para o uso de produtos fitossanitários de baixo impacto ao meio ambiente, em função da aplicação criteriosa e seletiva de pesticidas e c) selecionar produtos seletivos para a implantação do manejo integrado de pragas ou produção integrada do morangueiro no Brasil.

\section{MATERIAL E MÉTODOS}

\section{Obtenção e estabelecimento da criação de manutenção do ácaro-rajado (T. urticae)}

Os ácaros-praga foram obtidos em lavouras de morangueiros comerciais do município de Tocos do Mogi, MG e posteriormente levados ao Laboratório de Controle Biológico do Instituto Federal do Sul de Minas - IF Sul de Minas, Campus Inconfidentes, para dar início à criação de manutenção em casa de vegetação e laboratório.

Os ácaros foram mantidos em plantas de feijão-de-porco (Canavalia ensiformes) [Linnaeus] cultivadas em vasos e as plantas infestadas foram colocadas em casa de vegetação com temperatura média de $30 \pm 15^{\circ} \mathrm{C}$. As plantas de feijão-de-porco foram substituídas em intervalos regulares para garantir a qualidade do alimento fornecido aos indivíduos. 
Obtenção e criação de manutenção do ácaro predador (P. macropilis)

O ácaro predador foi obtido da criação de ácaros predadores da Embrapa Meio Ambiente, sendo posteriormente levado ao Laboratório de Controle Biológico do IF Sul de Minas, Campus Inconfidentes para dar início à criação de manutenção de manutenção.

Os predadores foram mantidos no interior de uma bandeja $35 \mathrm{~cm}$ de largura $\mathrm{x} 40$ $\mathrm{cm}$ de comprimento $\times 8 \mathrm{~cm}$ de profundidade, na qual foi colocada uma camada de espuma no fundo. Sobre a espuma foi colocada uma placa poliondas de PVC e sobre as bordas da placa foram colocadas tiras de algodão hidrófilo umedecido em água, criando assim uma arena que impediu a fuga dos espécimes. Montada a arena, adicionou-se água no fundo da bandeja para manter a umidade do algodão hidrófilo.

No interior da arena foram dispostas as folhas de feijão-de-porco ( $C$. ensiformes) infestadas com ácaro-rajado $T$. urticae como fonte de alimento para os ácaros predadores, essas folhas usadas foram substituídas assim que ácaro-rajado presente foi consumido e também em função do envelhecimento da folha. A bandeja com os ácaros foi mantida em câmara climática sob condições controladas a $25 \pm 2^{\circ} \mathrm{C}$, umidade relativa $70 \pm 10 \%$ e fotofase de 12 horas. Paralelamente, espécimes foram montadas em lâminas para certificação ou não da espécie a ser estudada.

A aplicação dos produtos sobre indivíduos adultos de $P$. macropilis foi realizada conforme metodologia recomendada pela "International Organization for Biological and Integrated Control of Noxious Animals and Plants (IOBC), West Palaearctic Regional Section (WPRS)" (Franz et al., 1980; Sterk \& Vanwestswinkel, 1988; Hassan, 1992; Hassan, 1994; Veire et al., 1996; Hassan, 1997; Degrande et al., 2002). A pulverização dos produtos em indivíduos de $P$. macropilis foi realizada por meio de pulverizadores manuais de $600 \mathrm{~mL}$ assegurando a aplicação de 1,5 a 2,0 $\mathrm{mg}$ de calda/cm2.

Tabela 1. Produtos fitossanitários utilizados para a avaliação da seletividade a Phytoseiulus macropilis.

\begin{tabular}{llccc}
\hline Ingrediente ativo & $\begin{array}{c}\text { Produto } \\
\text { Comercial }\end{array}$ & $\begin{array}{c}\text { Concentração/ } \\
\text { Formulação }\end{array}$ & $\begin{array}{c}\text { Dose } \\
\text { g i.a. L } \text { L }^{-1} \text { ága }\end{array}$ & Grupo Químico \\
\hline Abamectina & Vertimec & $18 \mathrm{CE}$ & 0,1 & avermectina \\
Fenpropatrina & Danimem & $300 \mathrm{CE}$ & 0,065 & piretróide \\
Propargito & Omite & $720 \mathrm{EC}$ & 0,03 & sulfito de alquila \\
Iprodiona & Rovral & $500 \mathrm{SC}$ & 0,15 & dicarboximida \\
Azoxistrobina & Amistar & $500 \mathrm{WG}$ & 0,02 & estrobilurinas \\
Enxofre & Kumulus & $800 \mathrm{DF}$ & 0,3 & inorgânico \\
Testemunha & Água & - & - & - \\
\hline
\end{tabular}

\section{Produtos utilizados para testes de seletivi- dade com $P$. macropilis}

Os produtos a serem estudados foram selecionados por serem registrados para uso na cultura do morangueiro e por serem produtos bastante utilizados na região sul de Minas Gerais (Tabela 1). O tratamento testemunha foi composto apenas por água destilada.

\section{Classificação dos produtos segundo escala de toxidade estabelecida pela IOBC}

Foi realizada a avaliação da mortalidade total dos indivíduos adultos após o período de contato com os produtos e os dados obtidos foram corrigidos pela fórmula de Abbott (1925). Em função da mortalidade apresentada pelos produtos, calculou-se o efeito total $(\mathrm{E} \%)$ utilizando-se da fórmula proposta por Bakker 
et al. (1992): $\mathrm{E}=100 \%-(100 \%-\mathrm{Ma})$, em que: $\mathrm{E}=$ efeito total $(\%)$ e $\mathrm{Ma}=$ mortalidade corrigida em função do tratamento testemunha (Abbott, 1925), em que: $\mathrm{Ma}=(\mathrm{Mt}-\mathrm{Mc}) /(100$ - Mc) x $100(\mathrm{Mt}=$ mortalidade observada no tratamento com o produto, $\mathrm{Mc}=$ mortalidade observada no tratamento testemunha).

Os produtos foram então, enquadrados em classes conforme a porcentagem de efeito total observado em: classe 1 = inócuos $(\mathrm{E}<30 \%)$, classe $2=$ levemente nocivos $(30 \% \leq \mathrm{E} \leq 80 \%)$, classe $3=$ moderadamente nocivos $(80 \%<\mathrm{E} \leq 99 \%)$ e classe $4=$ nocivos $(\mathrm{E}>99 \%)$, conforme escala proposta por membros da IOBC/WPRS (Bakker et al., 1992; Veire et al., 1996; Hassan, 1997; Degrande et al., 2002).

\section{Efeito dos produtos fitossanitários pulveri- zados diretamente sobre adultos de $P$. ma- cropilis}

Os bioensaios foram conduzidos no Laboratório de Controle Biológico do IF Sul de Minas, Campus Inconfidentes. Para avaliação dos efeitos dos produtos sobre os predadores, 40 indivíduos adultos com até 48 horas de idade, por tratamento, oriundos da criação em laboratório, foram acondicionadas em placas de Petri de $9 \mathrm{~cm}$ de diâmetro fechadas com filme plástico de PVC e levados à sala de aplicação.

Após a pulverização das caldas dos produtos descritos na Tabela 1, os indivíduos foram separados em 8 grupos de 5 espécimes cada e colocados sobre um disco foliar de feijão-de-porco de $6 \mathrm{~cm}$ de diâmetro, infestado com T. urticae (como alimento). $\mathrm{O}$ disco foi colocado sobre uma camada de algodão hidrófilo que foi mantido úmido dentro de uma placa de Petri de $9 \mathrm{~cm}$ de diâmetro, fechada com filme de PVC transparente. As placas foram mantidas em câmara climática sob condições controladas a $25 \pm 2^{\circ} \mathrm{C}$, umidade relativa $70 \pm 10 \%$ e fotofase de 12 horas. O disco foliar foi mantido por período de oito dias, sendo realizadas avaliações sobre a mortalidade.

A mortalidade dos ácaros foi avaliada nos intervalos de 24h, 48h, 72h, 96h e $120 \mathrm{~h}$ após a pulverização, com auxílio de um microscópio estereoscópico (40x), considerando morto o indivíduo que se manteve imóvel ao estímulo gerado pelo toque de um pincel.

\section{Avaliação da toxicidade residual dos pro- dutos a $P$. macropilis em laboratório.}

Para a realização desta etapa experimental, discos foliares de feijão-de-porco de $6 \mathrm{~cm}$ de diâmetro foram submetidos à pulverização com caldas dos produtos descritos na Tabela 1, em pulverizadores manuais, conforme mencionado anteriormente. $\mathrm{O}$ tratamento testemunha foi composto apenas por água destilada.

Uma hora após a pulverização, os discos foliares foram infestados com $T$. urticae, sendo posteriormente colocados 5 indivíduos de $P$. macropilis por disco, totalizando 40 ácaros predadores por tratamento. Em seguida o disco foi colocado sobre uma camada de algodão hidrófilo umedecida, dentro de uma placa de Petri de $9 \mathrm{~cm}$ de diâmetro, fechada com filme de PVC transparente. $\mathrm{O}$ experimento foi mantido em câmara climática sob condições controladas a $25 \pm 2^{\circ} \mathrm{C}$, umidade relativa $70 \pm 10 \%$ e fotofase de 12 horas. O disco foliar foi mantido por período de oito dias, sendo realizadas avaliações de mortalidade.

A mortalidade dos ácaros foi avaliada nos intervalos de 24h, 48h, 72h, 96h e 120 horas após a pulverização, com auxílio de um microscópio estereoscópico (40x). Foi considerado morto o indivíduo que se manteve imóvel ao estímulo gerado pelo toque de um pincel.

Os produtos foram classificados em função da mortalidade provocada nos indivíduos adultos, conforme o proposto pela IOBC. 
Efeito indireto dos produtos fitossanitários sobre indivíduos adultos de $P$. macropilis, pela ingestão de presas contaminadas.

Para a averiguação dos efeitos indiretos dos produtos fitossanitários sobre $P$. macropilis pela ingestão de ácaros T. urticae contaminados provenientes da criação, foram agrupados em placas de Petri de $15 \mathrm{~cm}$ de diâmetro $(\approx 400$ indivíduos por tratamento) e levados à pulverização. Os produtos foram aplicados na menor dosagem tóxica (próxima da $\mathrm{CL}_{50}$ ). Os produtos testados, em g de i.a. $\mathrm{L}^{-1}$ de água foram: abamectina $(0,01)$, fempropatrina $(0,03)$, propargito $(0,008)$, iprodiona $(0,15)$, azoxistrobina $(0,02)$ e enxofre $(0,3)$. Foi pulverizada apenas água destilada no grupo de ácarospresa a serem fornecidos como alimento para P. macropilis no tratamento controle. Após a pulverização, os indivíduos contaminados sobreviventes foram fornecidos como alimento a P. macropilis.

Vinte indivíduos de P. macropilis por tratamento foram individualizados e colocados em discos foliares de feijão-de-porco (3 $\mathrm{cm}$ de diâmetro), disposto sobre uma camada de algodão umedecido com água destilada, dentro de placas de Petri de $5 \mathrm{~cm}$ de diâmetro, fechadas com filme de PVC transparente. Para cada indivíduo foi disponibilizado ad libitum ácaros T. urticae previamente contaminados, como alimento.

Foi avaliada a mortalidade dos indivíduos de $P$. macropilis após a ingestão de presas contaminadas.

Os dados referentes à mortalidade acumulada dos indivíduos 24h, 48h, 72h, 96h e 120 horas foram submetidos à análise de variância em um modelo inteiramente ao acaso. Foram utilizadas oito repetições (para pulverização direta e toxicidade residual) e 5 repetições no teste de ingestão, utilizando-se o programa Sisvar (Ferreira, 2001). O teste de Scott e Knott, a 5\% de significância (Scott \& Knott, 1974) foi usado para comparar as mé- dias dos tratamentos, nos casos em que o teste F foi significativo.

\section{RESULTADOS E DISCUSSÃO}

\section{Efeito dos produtos fitossanitários pulveri- zados diretamente sobre adultos de $P$. $m a$ - cropilis}

Os resultados obtidos a partir dos efeitos causados a adultos de $P$. macropilis pela pulverização direta de produtos fitossanitários, após 24, 48, 72, 96, 120 horas são apresentados na Tabela 2.

$\mathrm{O}$ efeito de abamectina mostrou-se prejudicial para adultos de $P$. macropilis logo na primeira avaliação realizada às 24 horas após a pulverização. Abamectina causou uma mortalidade de $85 \%$ após 24 horas e $95 \%$ de mortalidade nas horas subseqüentes até a avaliação de 120 horas. As aplicações com os agrotóxicos propargito, iprodiona, azoxistrobina, enxofre e a testemunha não diferiram estatisticamente entre si, não apresentando, portanto toxicidade considerável para espécimes adultos de $P$. macropilis, com os resultados próximos ou inferiores à mortalidade observada no tratamento controle. Fempropatrina apresentou efeito intermediário com média de $35 \%$ de mortalidade 120 horas após aplicação (Tabela 2).

Em estudos de compatibilidade de agrotóxicos com os predadores $P$. macropilis e $N$. californicus Poletti et al. (2008) realizaram aplicações com fempropatrina, iprodiona e azoxistrobina sobre o predador $P$. macropilis. Os autores constataram que fempropatrina comportou-se como nocivo aos predadores, com $100 \%$ de mortalidade, diferindo dos resultados observados no presente estudo. Possivelmente, esta diferença pode estar relacionada às dosagens empregadas nos estudos, uma vez que os autores utilizaram $0,09 \mathrm{~g}$ i.a. $\mathrm{L}^{-1}$, contra $0,065 \mathrm{~g}$ i.a. $\mathrm{L}^{-1}$ utilizada neste estudo. Estes autores observaram ainda, que os fun- 
gicidas iprodiona e azoxistrobina se comportaram de maneira semelhante, não afetando a sobrevivência do predador.

\section{Avaliação da toxicidade residual dos produ- tos a $P$. macropilis em laboratório.}

Os compostos abamectina, azoxistrobina e enxofre provocaram efeito tóxico prejudicial ao predador, apresentando índices de mortalidade na avaliação de 120 horas de $62,5 \%$, $45 \%$ e $37,5 \%$ respectivamente (Tabela 3 ).

Em estudos com fungos, a ação do composto azoxistrobina ocorre na mitocôndria, bloqueando a transferência de elétrons e interrompendo a produção de energia, sem a qual o fungo não sobrevive (Sierotzki et al., 2000; Matheron, 2001; Souza \& Dutra, 2003). Assim, possivelmente o composto pode ter alterado o comportamento do $P$. $m a$ cropilis causando a mortalidade de alguns espécimes.

Verificou-se, ainda, que os valores obtidos com a aplicação de fempropatrina e propargito ambos registrados para a cultura do morangueiro para o controle do ácaro-rajado T. urticae e o fungicida iprodiona comportaram-se semelhante ao tratamento testemunha, portanto pelo contato com folhas tratadas com produtos fitossanitários.

Tabela 2. Mortalidade (\%) ( $\pm \mathrm{EP})$ de adultos de Phytoseiulus macropilis após 24, 48, 72, 96 e 120 horas desde a aplicação dos produtos fitossanitários. Temperatura de $25 \pm 2^{\circ} \mathrm{C}$, UR de $70 \pm 10 \%$ e fotofase de 12 horas. Inconfidentes, IF Sul de Minas, 2008.

\begin{tabular}{lrrrrr}
\hline \multirow{2}{*}{ Tratamentos } & $\mathbf{5 4 h}$ & $\mathbf{4 8 h}$ & $\mathbf{7 2 h}$ & $\mathbf{9 6 h}$ & $\mathbf{1 2 0 h}$ \\
\cline { 2 - 6 } & \multicolumn{2}{c}{ Mortalidade (\%) } \\
\hline Abamectina & $85,0 \pm 4,28 \mathrm{~b}$ & $95,0 \pm 4,28 \mathrm{~b}$ & $95,0 \pm 4,28 \mathrm{c}$ & $95,0 \pm 4,28 \mathrm{c}$ & $95,0 \pm 4,28 \mathrm{c}$ \\
Fempropatrina & $15,0 \pm 5,15 \mathrm{a}$ & $27,5 \pm 5,15 \mathrm{a}$ & $35,0 \pm 4,23 \mathrm{~b}$ & $35,0 \pm 4,23 \mathrm{~b}$ & $35,0 \pm 4,23 \mathrm{~b}$ \\
Propargito & $7,5 \pm 6,39 \mathrm{a}$ & $15,0 \pm 4,12 \mathrm{a}$ & $17,5 \pm 5,45 \mathrm{a}$ & $17,5 \pm 5,45 \mathrm{a}$ & $17,5 \pm 5,45 \mathrm{a}$ \\
Iprodiona & $5,0 \pm 7,01 \mathrm{a}$ & $15,0 \pm 6,94 \mathrm{a}$ & $17,5 \pm 6,19 \mathrm{a}$ & $17,5 \pm 6,19 \mathrm{a}$ & $17,5 \pm 6,19 \mathrm{a}$ \\
Azoxistrobina & $2,5 \pm 4,27 \mathrm{a}$ & $7,5 \pm 4,21 \mathrm{a}$ & $7,5 \pm 4,21 \mathrm{a}$ & $10,0 \pm 4,06 \mathrm{a}$ & $17,5 \pm 4,06 \mathrm{a}$ \\
Enxofre & $7,5 \pm 5,88 \mathrm{a}$ & $12,5 \pm 5,27 \mathrm{a}$ & $12,5 \pm 5,27 \mathrm{a}$ & $17,5 \pm 4,89 \mathrm{a}$ & $20,0 \pm 4,67 \mathrm{a}$ \\
Testemunha & $12,5 \pm 4,22 \mathrm{a}$ & $15,0 \pm 3,89 \mathrm{a}$ & $15,0 \pm 3,89 \mathrm{a}$ & $15,0 \pm 3,89 \mathrm{a}$ & $15,0 \pm 3,89 \mathrm{a}$ \\
\hline $\mathrm{CV}(\%)$ & 42,52 & 22,05 & 17,82 & 16,17 & 13,12 \\
\hline
\end{tabular}

Médias seguidas pela mesma letra na coluna não diferem estatisticamente entre si pelo teste de Scott e Knott $(\mathrm{P}>0,05)$.

Tabela 3. Mortalidade (\%) ( $\pm \mathrm{EP})$ de adultos de Phytoseiulus macropilis após 24, 48, 72, 96 e 120 horas desde o contato com folhas tratadas com produtos fitossanitários. Temperatura de $25 \pm 2^{\circ} \mathrm{C}$, UR de $70 \pm 10 \%$ e fotofase de 12 horas. Inconfidentes, IF Sul de Minas, 2008.

\begin{tabular}{lrrrrr}
\hline \multirow{2}{*}{ Tratamentos } & $\mathbf{5 4 h}$ & $\mathbf{4 8 h}$ & $\mathbf{7 2 h}$ & $\mathbf{9 6 h}$ & $\mathbf{1 2 0 h}$ \\
\cline { 2 - 6 } & $\mathbf{2 4 h}$ & \multicolumn{5}{c}{ Mortalidade (\%) } \\
\hline Abamectina & $17,5 \pm 5,45 \mathrm{~b}$ & $30,0 \pm 4,50 \mathrm{~b}$ & $47,5 \pm 8,42 \mathrm{~b}$ & $55,0 \pm 7,23 \mathrm{~b}$ & $62,5 \pm 7,29 \mathrm{~b}$ \\
Azoxistrobina & $22,5 \pm 6,25 \mathrm{~b}$ & $27,5 \pm 3,42 \mathrm{~b}$ & $32,5 \pm 4,42 \mathrm{~b}$ & $35,0 \pm 4,17 \mathrm{~b}$ & $45,0 \pm 5,26 \mathrm{~b}$ \\
Enxofre & $15,0 \pm 5,55 \mathrm{~b}$ & $22,5 \pm 4,52 \mathrm{~b}$ & $22,5 \pm 4,52 \mathrm{a}$ & $30,0 \pm 3,99 \mathrm{~b}$ & $37,5 \pm 4,58 \mathrm{~b}$ \\
Propargito & $5,0 \pm 2,25 \mathrm{a}$ & $15,5 \pm 3,60 \mathrm{a}$ & $20,0 \pm 5,54 \mathrm{a}$ & $30,0 \pm 5,75 \mathrm{~b}$ & $30,0 \pm 5,75 \mathrm{a}$ \\
Iprodiona & $2,5 \pm 1,50 \mathrm{a}$ & $7,5 \pm 2,94 \mathrm{a}$ & $10,0 \pm 4,61 \mathrm{a}$ & $12,5 \pm 4,22 \mathrm{a}$ & $12,5 \pm 4,22 \mathrm{a}$ \\
Fempropatrina & $0,0 \pm 0,00 \mathrm{a}$ & $2,5 \pm 1,05 \mathrm{a}$ & $7,5 \pm 3,42 \mathrm{a}$ & $7,5 \pm 3,42 \mathrm{a}$ & $7,5 \pm 3,42 \mathrm{a}$ \\
Testemunha & $10,0 \pm 2,50 \mathrm{a}$ & $12,5 \pm 3,38 \mathrm{a}$ & $17,5 \pm 4,09 \mathrm{a}$ & $17,5 \pm 4,09 \mathrm{a}$ & $22,5 \pm 3,88 \mathrm{a}$ \\
\hline $\mathrm{CV}(\%)$ & 74,08 & 34,65 & 39,23 & 33,74 & 12,33 \\
\hline
\end{tabular}

Médias seguidas pela mesma letra na coluna não diferem estatisticamente entre si pelo teste de Scott e Knott $(\mathrm{P}>0,05)$. 
Avaliação da mortalidade sobre indivíduos adultos de $P$. macropilis, pela ingestão de presas contaminadas

$\mathrm{O}$ efeito de abamectina mostrou-se prejudicial ao predador nas avaliações feitas a partir de 72 horas. Fempropatrina e propargito ambos acaricidas comportaram-se estatíticamente iguais a testemunha, portanto não mostraram índices de toxicidade considerável ao predador (Tabela 4).

Iprodiona, azoxistrobina e enxofre também não difereriram estatísticamente do controle, não sendo considerados tóxicos ao predador pela ingestão de presas contaminadas com esses compostos.
A ação do abamectina sobre os artrópodes revela-se como efeito calmante, semelhante ao ácido gama-aminobutírico (GABA) (Cleland, 1996). Além desse efeito, pesquisas evidenciaram que as avermectinas podem ainda atuar sobre proteínas dos canais de cloro encontradas apenas em invertebrados, promovendo uma maior especificidade e acentuando o efeito deste composto sobre insetos e ácaros (Scott \& Duce, 1987; Martin \& Pennington, 1988, Martin et al., 2002). Assim, no presente estudo o composto pode ter provocado redução das atividades do predador, além da redução do metabolismo, provocando a sua morte.

Tabela 4. Mortalidade (\%) ( \pm EP) de adultos de Phytoseiulus macropilis após 24, 48, 72,96 e 120 horas desde a ingestão de presas contaminadas com produtos fitossanitários. Temperatura de $25 \pm 2{ }^{\circ} \mathrm{C}$, UR de $70 \pm 10 \%$ e fotofase de 12 horas. Inconfidentes, IF Sul de Minas, 2008.

\begin{tabular}{lcrrrr}
\hline \multirow{2}{*}{ Tratamentos } & \multicolumn{5}{c}{ Mortalidade (\%) } \\
\cline { 2 - 6 } & $\mathbf{2 4 h}$ & \multicolumn{1}{c}{$\mathbf{4 8 h}$} & $\mathbf{7 2 h}$ & \multicolumn{1}{c}{$\mathbf{9 6 h}$} & $\mathbf{1 2 0 h}$ \\
\hline Abamectina & $0,0 \pm 0,00 \mathrm{a}$ & $20,0 \pm 4,35 \mathrm{a}$ & $40,0 \pm 4,90 \mathrm{~b}$ & $46,6 \pm 7,90 \mathrm{~b}$ & $46,6 \pm 7,90 \mathrm{~b}$ \\
Fempropatrina & $6,6 \pm 1,94 \mathrm{a}$ & $6,6 \pm 1,94 \mathrm{a}$ & $6,6 \pm 1,94 \mathrm{a}$ & $6,6 \pm 1,94 \mathrm{a}$ & $6,6 \pm 1,94 \mathrm{a}$ \\
Propargito & $6,6 \pm 1,94 \mathrm{a}$ & $20,0 \pm 4,51 \mathrm{a}$ & $20,0 \pm 4,51 \mathrm{a}$ & $20,0 \pm 4,51 \mathrm{a}$ & $33,4 \pm 6,32 \mathrm{a}$ \\
Iprodiona & $6,6 \pm 2,15 \mathrm{a}$ & $13,2 \pm 5,12 \mathrm{a}$ & $13,2 \pm 5,12 \mathrm{a}$ & $13,2 \pm 5,12 \mathrm{a}$ & $19,8 \pm 8,30 \mathrm{a}$ \\
Azoxistrobina & $0,0 \pm 0,00 \mathrm{a}$ & $0,0 \pm 0,00 \mathrm{a}$ & $0,0 \pm 0,00 \mathrm{a}$ & $0,0 \pm 0,00 \mathrm{a}$ & $13,2 \pm 5,26 \mathrm{a}$ \\
Enxofre & $0,0 \pm 0,00 \mathrm{a}$ & $0,0 \pm 0,00 \mathrm{a}$ & $0,0 \pm 0,00 \mathrm{a}$ & $0,0 \pm 0,00 \mathrm{a}$ & $0,0 \pm 0,00 \mathrm{a}$ \\
Testemunha & $0,0 \pm 0,00 \mathrm{a}$ & $0,0 \pm 0,00 \mathrm{a}$ & $9,8 \pm 3,02 \mathrm{a}$ & $13,8 \pm 3,70 \mathrm{a}$ & $13,8 \pm 3,70 \mathrm{a}$ \\
\hline $\mathrm{CV}(\%)$ & 81,57 & 73,72 & 34,26 & 54,50 & 48,02 \\
\hline
\end{tabular}

Médias seguidas pela mesma letra na coluna não diferem estatisticamente entre si pelo teste de Scott e Knott $(\mathrm{P}>0,05)$.

\section{Classificação dos produtos quanto ao efeito total sobre $P$. macropilis, segundo escala de toxidade estabelecida pela IOBC}

Abamectina foi o único produto considerado moderadamente tóxico ao predador, sendo enquadrado na classe 3 , quando pulverizado diretamente sobre os espécimes. Fempropatrina, apesar do significativo efeito prejudicial observado, foi inócuo ao predador. Os compostos propargito, iprodiona, azoxistrobina e enxofre mostraram-se inócuos aos espécimes tratados (Classe 1) (Tabela 5).
Quando aplicado sobre discos foliares de C. ensiformes, abamectina foi o único produto a provocar redução na sobrevivência, sendo considerado levemente nocivo ao predador (Classe 2), enquanto que os demais se apresentaram inócuos (Tabela 6).

O contato do predador com os compostos por meio da ingestão de presas contaminadas apresentou resultados semelhantes, sendo abamectina enquadrado na classe 2 e propargito, iprodiona, azoxistrobina e enxofre inócuos ao inimigo natural (Classe 1) (Tabela 7). 
Tabela 5. Efeito de produtos fitossanitários sobre a mortalidade (\%) de Phytoseiulus macropilis tratados na fase adulta, efeito (E) (\%) e classificação pela escala de toxicidade proposta pela IOBC. Temperatura de $25 \pm 2^{\circ} \mathrm{C}$, UR de $70 \pm 10 \%$ e fotofase de 12 horas. Inconfidentes, IF Sul de Minas, 2008.

\begin{tabular}{lclccc}
\hline Tratamentos & No espécimes & Mortalidade & Ma (\%) & E (\%) & Classe $^{\mathbf{3}}$ \\
\hline \multicolumn{5}{c}{ Adultos - Pulverização direta } \\
\hline Abamectina & 40 & 95,0 & 94,11 & 94,11 & 3 \\
Fempropatrina & 40 & 35,0 & 23,53 & 23,53 & 1 \\
Propargito & 40 & 17,5 & 2,94 & 2,94 & 1 \\
Iprodiona & 40 & 17,5 & 2,94 & 2,94 & 1 \\
Azoxistrobina & 40 & 17,5 & 2,94 & 2,94 & 1 \\
Enxofre & 40 & 20,0 & 5,88 & 5,88 & 1 \\
Testemunha & 40 & 15,0 & - & - & - \\
\hline
\end{tabular}

${ }^{1}$ Mortalidade corrigida conforme a fórmula de Abbott (1925): Ma $=(\mathrm{Mt}-\mathrm{Mc}) /(100-\mathrm{Mc}) \times 100 ;{ }^{2}$ Efeito total do produto sobre o inimigo natural, onde: $\mathrm{E}=100 \%$ - $\left(100 \%\right.$ - Ma); ${ }^{3}$ Classe de toxicidade: classe 1 = Inócuo $(\mathrm{E}<30 \%)$, classe 2 $=$ levemente nocivo $(30 \% \leq \mathrm{E} \leq 80 \%)$, classe $3=$ moderadamente nocivo $(80 \%<\mathrm{E} \leq 99 \%)$ e classe $4=$ nocivo $(\mathrm{E}>99 \%)$ (Veire et al., 2002).

Tabela 6. Efeito de produtos fitossanitários sobre a mortalidade (\%) de Phytoseiulus macropilis após contato com superfície tratada, efeito (E) (\%) e classificação pela escala de toxicidade proposta pela IOBC. Temperatura de $25 \pm 2^{\circ} \mathrm{C}$, UR de $70 \pm 10 \%$ e fotofase de 12 horas. Inconfidentes, IF Sul de Minas, 2008.

\begin{tabular}{lclccc}
\hline Tratamentos & $\mathbf{N}^{\mathbf{0}}$ espécimes & Mortalidade & Ma (\%) & $\mathbf{E}(\%)^{\mathbf{2}}$ & Classe $^{\mathbf{3}}$ \\
\hline Abamectina & \multicolumn{5}{c}{ Adultos - Superfície tratada } \\
Fempropatrina & 40 & 62,5 & 51,6 & 51,6 & 2 \\
Propargito & 40 & 7,5 & 0,0 & 0,0 & 1 \\
Iprodiona & 40 & 30,0 & 9,7 & 9,7 & 1 \\
Azoxistrobina & 40 & 12,5 & 0,0 & 0,0 & 1 \\
Enxofre & 40 & 45,0 & 29,1 & 29,1 & 1 \\
Testemunha & 40 & 37,5 & 19,4 & 19,4 & 1 \\
\end{tabular}

${ }^{1}$ Mortalidade corrigida conforme a fórmula de Abbott (1925): Ma=(Mt-Mc) $/(100-\mathrm{Mc}) \times 100 ;{ }^{2}$ Efeito total do produto sobre o inimigo natural, onde: $\mathrm{E}=100 \%-\left(100 \%\right.$ - Ma); ${ }^{3}$ Classe de toxicidade: classe $1=$ Inócuo $(\mathrm{E}<30 \%)$, classe 2 $=$ levemente nocivo $(30 \% \leq \mathrm{E} \leq 80 \%)$, classe $3=$ moderadamente nocivo $(80 \%<\mathrm{E} \leq 99 \%)$ e classe $4=$ nocivo $(\mathrm{E}>99 \%)$ (Veire et al., 2002).

Tabela 7. Efeito de produtos fitossanitários sobre a mortalidade (\%) de Phytoseiulus macropilis desde a ingestão de presas contaminadas com produtos fitossanitários, efeito (E) (\%) e classificação pela escala de toxicidade proposta pela IOBC. Temperatura de $25 \pm 2^{\circ} \mathrm{C}$, UR de $70 \pm 10 \%$ e fotofase de 12 horas. Inconfidentes, MG, IF Sul de Minas, 2008.

\begin{tabular}{|c|c|c|c|c|c|}
\hline Tratamentos & $\mathrm{N}^{0}$ espécimes & Mortalidade & Ma (\%) $)^{1}$ & $E(\%)^{2}$ & Classe $^{3}$ \\
\hline & \multicolumn{5}{|c|}{ Adultos - Ingestão de presas contaminadas } \\
\hline Abamectina & 15 & 46,6 & 38,1 & 38,1 & 2 \\
\hline Fempropatrina & 15 & 6,6 & 0,0 & 0,0 & 1 \\
\hline Propargito & 15 & 33,4 & 22,7 & 22,7 & 1 \\
\hline Iprodiona & 15 & 19,8 & 6,9 & 6,9 & 1 \\
\hline Azoxistrobina & 15 & 13,2 & 0,0 & 0,0 & 1 \\
\hline Enxofre & 15 & 0,0 & 0,0 & 0,0 & 1 \\
\hline Testemunha & 15 & 13,8 & & & - \\
\hline
\end{tabular}

${ }^{1}$ Mortalidade corrigida conforme a fórmula de Abbott (1925): $\mathrm{Ma}=(\mathrm{Mt}-\mathrm{Mc}) /(100-\mathrm{Mc}) \times 100 ;{ }^{2}$ Efeito total do produto sobre o inimigo natural, onde: $\mathrm{E}=100 \%$ - $\left(100 \%\right.$ - Ma); ${ }^{3}$ Classe de toxicidade: classe $1=$ Inócuo $(\mathrm{E}<30 \%)$, classe 2 $=$ levemente nocivo $(30 \% \leq \mathrm{E} \leq 80 \%)$, classe $3=$ moderadamente nocivo $(80 \%<\mathrm{E} \leq 99 \%)$ e classe $4=$ nocivo $(\mathrm{E}>99 \%)$ (Veire et al., 2002). 


\section{CONCLUSÕES}

Para as condições de desenvolvimento do presente estudo, foi possível concluir:

Abamectina foi prejudicial à sobrevivência do predador P. macropilis e foi classificado como moderadamente nocivo (Classe 3) para aplicação direta;

Abamectina apresentou-se levemente nocivo (Classe 2) quando o contato do predador ocorreu em superfície tratada ou pelo consumo de presas contaminadas;

Os compostos fempropatrina, propargito, iprodiona, azoxistrobina e enxofre foram inócuos ao predador $P$. macropilis independente da forma de exposição.

A utilização do ácaro predador $P$. $m a-$ cropilis, associado aos compostos de baixa toxicidade, pode apresentar grande utilidade em programas de manejo integrado de $T$. urticae nas lavouras de morangueiros no Brasil, principalmente aquelas conduzidas sob o sistema da PIMo.

Agradecimentos: Os autores agradecem a Fundação de Amparo à Pesquisa do Estado de Minas Gerais - FAPEMIG pelo apoio financeiro para a execução do projeto.

\section{REFERÊNCIAS BIBLIOGRÁFICAS}

ABBOTT, W.S. A method of computing the effectiveness of an insecticide. Journal of Economic Entomology, Lanham, v.15, p.265267, 1925.

ALI, F.S. Life tables of Phytoseiulus macropilis (Banks) (Gamasida: Phytoseiidae) at different temperatures. Experimental Applied Acarology, v.22, p.335-342, 1998.

ANTUNES, L.E.C.; FILHO, J.D.; CALEGARIO, F.F.; COSTA, H.; JÚNIOR, C.R. Produção integrada de morango (PIMo) no Brasil. Informe Agropecuário, Belo Horizonte, v.28, n.236, p.34-39, 2007.
BAKKER, F.; GROVE, A.; BLUMEL, S.; CALIS, J.; OOMEN, P. Side-effect tests for Phytoseiids and their rearing methods. In: INTERNATIONAL ORGANIZATION FOR BIOLOGICAL CONTROL OF NOXIOUS ANIMALS AND PLANTS. Working Group "Pesticides and Beneficial Organisms". Bulletin SROP, Montfavet, v.15, n.3, p.61-81, 1992.

CLELAND, T. A. Inhibitory glutamate-receptor channels. Molecular Neurobiology, Firenze, v.13, n.2, p.97-136, 1996.

DEGRANDE, P.E.; REIS, P.R.; CARVALHO, G.A.; BELARMINO, L.C. Metodologia para avaliar o impacto de pesticidas sobre inimigos naturais p.71-94. In: PARRA, J.R.P.; BOTELHO, P.S.M.; CORRÊA-FERREIRA, B.; BENTO, J.M.S. (Ed.). Controle biológico no Brasil: parasitóides e predadores. São Paulo, Manole, 2002, 635p.

FADINI, M.A.M.; ALVARENGA, D. Pragas do morangueiro. Informe Agropecuário, Belo Horizonte, v.20, n.198, p.75-79, 1999.

FERREIRA, D.F. Análises estatísticas por meio do Sisvar para Windows versão 4.0. In: REUNIÃO ANUAL DA REGIÃO BRASILEIRA DA SOCIEDADE INTERNACIONAL DE BIOMETRIA, 45., 2000, São Carlos. Anais... São Carlos, SP: UFSCar, 2000. p.255-258.

FRANZ, J. M.; BOGENSCHÜTZ, H.; HASSAN, S.A.; HUANG, P.; NATON, E.; SUTER, H.; VIGGIANI, G. Results of a joint pesticide test programme by the working group: "Pesticides and Beneficial Arthropods". Entomophaga, Paris, v.25, n.3, p.231-236, 1980.

GARCIA, I.P.; CHIAVEGATO, L.G. Respostas funcional e reprodutiva de Phytoseiulus macropilis (Banks, 1905) (Acari: Phytoseiidae) a diferentes densidades de ovos de Tetranychus 
urticae (Koch, 1836) (Acari: Tetranychidae). Científica, v.25, p.35-43, 1997.

HASSAN, S.A. Guideline for the evaluation of side-effects of plant protection product on Trichogramma cacoeciae. In: INTERNATIONAL ORGANIZATION FOR BIOLOGICAL CONTROL OF NOXIOUS ANIMALS AND PLANTS. Working Group "Pesticides and Beneficial Organisms". Bulletin SROP, Montfavet, v.15, n.3, p.18-39, Apr. 1992.

HASSAN, S.A. Métodos padronizados para testes de seletividade com ênfase em Trichogramma. In: PARRA, J.R.P.; ZUCCHI, R. (Eds.). Trichogramma e o controle biológico aplicado. Piracicaba: FEALQ, 1997. Cap. 8, p.207-233.

HASSAN, S.A. Production of the angoumois grain Sitotroga cerealella (Oliv.) as alternative host for egg parasites. In: GERDING, P. M. (Ed.). Taller internacional producción y utilización de Trichogramma para el control biológico de plagas. Chillán: INIA/Quilamapu, 1994. p.20-26.

MARTIN, R. J.; PENNINGTON, A. J. Effect of dihydroavermectin-bla on CI single-channel currents in Ascaris. Pesticide Science, Sussex, v. 24, n. 1, p.90-91, 1988.

MARTIN, R. J.; ROBERTSON, A. P.; WOLSTENHOLME, A. J. Macrocyclic lactones In: VERCRUYSSE, J.; REW, R. S. Antiparasitic therapy. [S. 1.]: CAB International, 2002.

MATHERON, M. E. Modes of action for plant disease management chemistries. In: ANNUAL DESERT VEGETABLE CROP WORKSHOP, 11., YUMA, AZ, 2001. Yuma Agricultural Center... Yuma, Az: [S. 1.] 2001.

MCMURTRY, J.A.; CROFT, B.A. Life styles of phytoseiid mites and their roles as biologi- cal control agents. Annual Review of Entomology, v.42, p.291-321, 1997.

MCMURTRY, J.A.; HUFFAKER, C.B.; VAN DE VRIE, M. Ecology of tetranychid mites and their natural enemies: a review. I. Tetranychid enemies: their biological characters and the impact of spray practices. Hilgardia, v.40, p.331-390, 1970.

MORAES, G.J. Controle biológico de ácaros fitófagos com predadores, p.225-237.. In PARRA, J.R.P.; BOTELHO, P.S.M.; CORRÊA-FERREIRA, B.; BENTO, J.M.S. (Ed.). Controle biológico no Brasil: Parasitóides e predadores. São Paulo, Manole, 2002, 635p.

POLETTI, M.; COLLETTI, L.P; OMOTO, C. Compatibilidade de Agrotóxicos com os Ácaros Predadores Neoseiulus californicus (McGregor) e Phytoseiulus macropilis (Banks) (Acari: Phytoseiidae). BioAssay, v.3, n.3, p.01-14, 2008.

RESENDE, L.M.A.; MASCARENHAS, M.H.T.; PAIVA, B.M. Panorama da produção e comercialização de morango. Informe Agropecuário, Belo Horizonte, v.20, n.198, p.5-19, 1999.

SATO, M.E.; SUPLICY FILHO, N.; SOUZA FILHO, M.F.;TAKEMATSU, A.P. Resistência do ácaro-rajado Tetranychus urticae (Koch, 1836) (Acari: Tetranychidae) a diversos acaricidas em morangueiro (Fragaria sp.) nos municípios de Atibaia-SP e Piedade-SP. Ecossistema, v.19, p.40-46, 1994.

SCOTT, A.J.; KNOTT, M.A. A cluster analyses method for grouping means in the analyses of variance. Biometrics, Oxford, v.30, p.502$512,1974$.

SCOTT, R. H.; DUCE, I. R. Pharmacology of GABA receptors on skeletal muscle fibres of 
the locust (Schistocerca gregaria). Comparative Biochemistry and Physiology, Oxford, v.86, n.2, p.305-311, 1987.

SIEROTZKI， H.; WULLSCHLEGER， J.; GISI, U. Point mutation in cytochrome b gene conferring resistance to strobilurin fungicides in Erysiphe graminis f. sp. tritici field isolates. Pesticide Biochemistry and Physiology, San Diego, v.68, n.2, p.107-112, Oct. 2000.

SILVA， F.R.; VASCONCELOS， G.J.N.; GONDIM JUNIOR., M.G.C.; OLIVEIRA, J.V. Exigências térmicas e tabela de fertilidade de Phytoseiulus macropilis (Banks) (Acari: Phytoseiidae). Neotropical Entomology, Londrina, v.34, n.2, p.291-296, 2005.

SIMÕES, J.C.; FADINI, M.A.M.; VENZON, M. Manejo integrado de pragas na cultura do morangueiro. Informe Agropecuário, Belo Horizonte, v.28, n.236, p.56-63, 2007.

SOUZA, P. E.; DUTRA, M. R. Fungicidas no controle e manejo de doenças de plantas. Lavras: UFLA, 2003. 145 p. il.

STERK, G.; VANWETSWINKEL, G.; A field method for testing for the side-effects of pesticides on the predatory mite Amblyseius finlandicus (oud.) (Phytoseiidae: Acari). IOBC/ WPRS. Bulletin, 1988/IX/4, p.137.
VAN DE VRIE, M.; MCMURTRY, J.A.; HUFFAKER, C.B. Ecology of tetranychid mites and their natural enemies: A review. III. Biology, ecology, and pest status, and hostplant relations of tetranychids. Hilgardia, v.41, p.387-403, 1972.

VEIRE, M.; SMAGGHE, G.; DEGHEELE, D. A laboratory test method to evaluate the effect of 31 pesticides on the predatory bug, Orius laevigatus (Heteroptera: Anthocoridae). Entomophaga, Paris, v.41, n.2, p.235-243, 1996.

VEIRE, van de; STERK, G.; van de STAAIJ, M.; RAMAKERS, P.M.J.; TIRRY, L. Sequential testing scheme for the assessment of the side-effects of plant protection products on the predatory bug Orius laevigatus. BioControl, Dordrecht, v.47, n.1, p.101-113, Feb. 2002.

WETZEL, C.; DICKLER, E. Side effects of sulphur and a natural pyrethroid on Trichogramma dendrolimi Matsumura (Hym., Trichogrammatidae) in apple orchards. In: INTERNATIONAL ORGANIZATION FOR BIOLOGICAL CONTROL OF NOXIOUS ANIMALS AND PLANTS. Working group "pesticides and beneficial organisms. Bulletin SROP, 17/10, Montfavet, 1994. p.123131. 